\title{
La ciudad en la música. Vertientes de análisis
}

\author{
The city in music. Lines of analysis
}

Alma Delia Juárez-Sedano ${ }^{a}$

\begin{abstract}
:
This proposal proposes to understand the city from popular music through three aspects. It emphasizes the phenomenology of sound and involves both the work of the author and the meanings of listeners. The method used contemplates sampling in Mexico City, indepth interviews and an analysis of the discourse. Giving, with it, reference of the points of view of the author of the work, of the interpretations to which it gives pattern once listened and of the affections positioned.
\end{abstract}

\section{Keywords:}

The point of view, the evoked place, the urban imaginary, the urban listener

\section{Resumen:}

Esta propuesta plantea entender a la ciudad desde la música popular a través de tres vertientes. Hace énfasis en la fenomenología del sonido e implica, tanto a la obra del autor, como a las acepciones de los escuchas. El método utilizado contempla muestreos en la Ciudad de México, entrevistas a profundidad y un análsis del discurso. Dando, con ello, referecia de los puntos de vista del autor de la obra, de las interpretaciones a las que da pauta una vez escuchada y de las afecciones posicionadas.

\section{Palabras Clave:}

El punto de vista, el lugar evocado, el imaginario urbano, el escuchario urbano

\section{Introducción}

La ciudad es un fenómeno social en la que se desarrollan una infinidad de actividades. Analizarla desde la música sugiere pensarla como una representación cultural colectiva en la que interacciona la escucha. En este trabajo, la ciudad se precisa desde una aproximación fenomenológica, la música popular como parte de la experiencia del habitante y el referente que da pauta a la configuración del fenómeno urbano, desde el cuerpo vivido.

El caso de estudio es Ciudad de México. La cual, desde una perspectiva musical se vislumbra en los ambientes populares. La música como producto de la ciudad, teniendo de referencia la triada conceptual propuesta por (Lefevbre, 2013), representa al lugar y es lugar de representación, ya que da cuenta de los significados que le otorgan tanto los escuchas como los compositores musicales. El planteamiento de este trabajo sostiene que la música habla de la ciudad desde la perspectiva del autor y la interpretación del escucha. Así, la ciudad puede ser entendida desde tres vertientes: la narrativa, la sonoridad y el escuchario.

En este sentido, el presente artículo, dividido en tres apartados, propone definir cada una de las vertientes, a apartir de un análisis cualitativo-explicativo que involucra la fenomenología del sonido, analizada a partir de los significados, la experiecia urbana, el lugar evocado y las identidades urbanas.

\section{Desarrollo}

Autor de Correspondencia, Universidad Autónoma del Estado de Hidalgo, https://orcid.org/0000-0001-8279-7997, Email: ajuarez@uaeh.edu.mx 
La narrativa musical se vislumbra como una representación del punto de vista ciudadano* que hace énfasis en uno o varios hechos determinados. En ella, se crea la ocasión del encuentro entre lo real y lo imaginado, entre lo sentido y lo vivido. La narrativa musical es una de las formas de representar el imaginario y, a su vez, es una de las maneras de entenderlo. El lenguaje utilizado en ella es parte medular. Su estructura muestra la historia del o los personajes, al dejar ver, a través de ella, las acciones que ejercen éstos, en un tiempo y un lugar determinado.

La narrativa musical se puede analizar en tres sentidos. Primero, como estrategia de análisis de un hecho determinado. Segundo, como elemento de observación entre lo real y lo imaginado, que develan en parte las vivencias y contextos que el autor de la obra ha vivido. Tercero, como patrimonio cultural que da pauta a la empatía, al traer a la mente recreaciones específicas vividas por el escucha.

\section{Fragmento I}

Desde las diez ya no hay donde parar el coche, ni un ruletero que lo quiera a uno llevar,

llegar al centro atravesarlo es un desmoche, un hormiguero no tiene tanto animal.

Chava Flores, Sábado Distrito Federal

(Canción creada entre 1950-1970)

Como estrategia de ánalisis, en este fragmento Chava Flores describe al centro de la Ciudad de México a una hora determinada del día. En él, muestra a una ciudad congestionada de tráfico, falta de transporte que le permita a alguien conducirse a su destino y conglomerada de gente. Como elemento de observación el autor, hace uso de su imaginación al comparar a este centro con un hormiguero y se plantea, dentro de la historia, como personaje. Como patrimonio cultural, una vez escuchada esta canción, pueden venir a la mente imágenes actuales del centro histórico dado que las condiciones no han cambiado mucho, al contrario, la cantidad de personas que la circulan va en aumento.

Fragmento II

Difícil es caminar, en un extraño lugar, en donde el hambre se ve, como un circo en acción. en las calles no hay telón, así que puedes mirar, como rico espectador, te invito a nuestra ciudad.
La Maldita Vecindad y Los Hijos del Quinto Patio, Un

gran circo

(1991)

En el fragmento II, La Maldita Vecindad y Los Hijos del Quinto Patio, por un lado, muestran, a través de su narrativa, una ciudad con habitantes que viven en la informalidad. La precariedad económica es la protagonista en este espectáculo de imágenes, creadas a través de las funciones clandestinas que ofrecen los habitantes de más bajos recursos, con la finalidad de obtener un ingreso económico. El discurso completo de la canción se posiciona en las actividades que se desarrollan en los semáforos. Donde, un alto y un siga, pueden significar una moneda más para el habitante, cuyo trabajo implica brindar entretenimiento a los que circulan las calles en sus autos. Por otro lado, deja ver a los conductores como adinerados.

En los dos fragmentos se habla de la Ciudad de México pero en diferentes épocas. En ambas se muestra a los espectadores como personajes de la historia que viven la ciudad. Las dos narrativas revelan acciones que se desarrollan en la ciudad y que pueden asociarse a momentos y lugares de la época actual.

Aunque las acciones planteadas por Chava Flores, en la canción Sábado Distrito Federal, no son exactamente las mismas a las de la época actual, el imaginario que se recrea, una vez escuchada la canción, puede ser similar y traer a la mente imágenes específicas como Av. 5 de mayo, el Zócalo de la Cd. de México en época navideña (de manera muy específica) y Av. Madero, por mencionar algunas.

La acción imaginativa, que puede producir una canción, responde según la experiencia y puede ser asociada a cualquier centro de ciudad si se lee el mismo mensaje que muestra el autor de la obra. En la actualidad, los centros de las ciudades se perciben atiborrados de personas, por lo que, si el urbanita escucha este fragmento, las imágenes que vendrán a su mente corresponderán específicamente a las creadas por su cuerpo vivido.

Entonces, las interpretaciones de la narrativa, se tienen que dar por la combinación de tres condicionantes, los contextos reales que dieron pauta a la canción, el imaginario del autor de la obra y el imaginario al cual se asocia en el escucha una vez enunciada la canción. Las palabras configuran la escena y ponen a trabajar a la imaginación una vez escuchadas de forma estructurada.

\footnotetext{
* El punto de vista ciudadano es término empleado por Silva (2006, p. 44)
} 
Así, la información que dota la narrativa en la música al ser escuchada, revela ideas de hechos, tanto imaginados como reales y, generalmente, se asocian a los imaginarios, que se configuran a partir de los hechos vividos en el territorio urbano. Esta información, al estar acompañada de una sonoridad musical y una enunciación específica, genera en el escucha sentimientos y emociones a través de las vibraciones sonoras que recibe el cuerpo.

El sentido y significado, que se le otorga a lo escuchado, responde a lo que el escucha ha vivido y a las relaciones que se puedan generar una vez enunciada. Por lo que, es en este sentido que tiene que ser interpretada. "La interpretación debe ser, a su vez, evaluada dentro de una concepción histórica de la conciencia humana" (Sontang, 1984: 19). Comprender la narrativa de una canción, implica insertarla en el tiempo en el que fue creada, visualizar los contextos del autor de la obra y tener presente la cultura en la que es escuchada.

La narrativa es un legado en el cual se refugia el habitante, añorando lo que fue y asemejándolo con lo que es. La narrativa de hace 20, 30, o 50 años, se sigue escuchando en el transporte público, en los paraderos de los autobuses y en las estaciones de la radio, haciendo con ello que los habitantes la tengan presente como parte de su vida cotidiana.

Esa idea que, en un momento dado, el autor se imaginó, dio pauta a la canción y, aunque los lugares asociados de hace cuarenta años siguen ahí, pueden no conservar las mismas características con las que fueron descritos y parecer otros. Asimismo, estos lugares imaginados hace décadas, pueden tener gran similitud con los que se viven en la actualidad y no precisamente ser los imaginados por el autor. Es así que la narrativa trasciende los contextos en los que fue creada y puede dar pie a la creación de un imaginario colectivo no sólo de una ciudad, sino de múltiples ciudades que se configuran bajo ciertos patrones de semejanza.

Si se considera que la narrativa musical es portadora de información signada, revela entonces, en parte, el imaginario del autor que la crea y puede dar pie a configuraciones colectivas una vez escuchada, siempre que ésta genere empatía en sus escuchas.

Fragmento III

Sirvió a su esposo, vistió a los niños, cambió pañales, sirvió los panes,

llevó a sus hijos para la escuela, pensó en la dieta que se comían, compró verduras, midió el dinero, palpó lo gris de su economía, formó en la cola de las tortillas, cargó a Francisco, miró la calle, por todas partes había mujeres, todas compraban y se movían,

cumplían airadas con sus deberes, le recordaban a las hormigas, sintió de pronto que eran esclavas, sintió que todas eran amigas.

León Chávez Texeiro, La mujer (Se va la vida).

En el fragmento III, la canción habla de las actividades cotidianas desempeñadas por una ama de casa, de clase baja, en la ciudad. Que se encuentra asignada únicamente a las actividades del hogar, que implican principalmente hacerse cargo del aseo de la casa y de la crianza de los hijos. Actividades que le ocupan todo el día, todos los días de la semana. Aquí, nuevamente, se hace una analogía de la vida de la ciudad con las hormigas, pero en este caso se asocia a su forma resignada de trabajar sin descanso.

"La música forma parte de los medios de expresión a través de los cuales podemos estudiar los cambios y transformaciones de una ciudad" (Viñuela, 2010: 16). Hoy en día, es difícil imaginar a una mujer desempeñándose como ama de casa únicamente. Las condiciones económicas bajo las que vive el país han propiciado su inserción en los ambientes laborales, delegando la responsabilidad a los hijos de mayor edad.

'Por "punto de vista ciudadano" entendiendo, precisamente, una serie de estrategias discursivas por medio de las cuales los ciudadanos narran las historias de su ciudad, aun cuando tales relatos pueden, igualmente, ser representados en imágenes visuales' (Silva A. , 2006: 45).

El punto de vista, como estrategia discursiva, da a conocer una postura que será definida al relacionar los hechos con la información previa acumulada. La ciudadania, describe circunstancias, momentos, también emociones y sentimientos. Su representatividad dependerá esta vez no sólo de quien lo da, sino de quien, a partir de él, construye uno propio. Los ciudadanos, cuando describen los hechos de la ciudad, no sólo están dando a conocer lo que ellos perciben del entorno, sino que, también, narran la manera en la que ellos viven y entienden determinados hechos. Por lo que, la forma de interpretar estos puntos de vista, dependerá de la manera en la que son representados y 
vividos. El punto de vista ciudadano, es entonces, una estrategia discursiva con la cual ellos dan a conocer la realidad, aporta información al dotar de sentido lo narrado. La construcción del discurso da lugar a un juicio de valor que pondera tanto sentimientos, como emociones, situando hechos y lugares.

Cuando el urbanita, recolecta información a través del cuerpo, en su paso por el territorio, crea supuestos que le permiten dar coherencia a lo existente y es, a partir de ellos, que configura un criterio propio, establecido por las experiencias tanto del cuerpo vivido, como de las experiencias que se generan a partir de otros puntos de vista materializados en libros, canciones, imágenes, esculturas, ciudades. La ciudad, como una totalidad, hace pensar en la infinidad de problemas, en la belleza de sus edificaciones, en la inseguridad, en la cultura y en las artes, dando pauta a la inspiración, expresando con ellos el punto de vista, ya sea por hartazgo o por fascinación, a través de las materializaciones textuales y figurativas. Ejemplo de ello es lo que se sabe o se puede imaginar cuando se escucha el nombre de Venecia, París, México, Tokio o Bombay.

\section{La sonoridad musical}

Los habitantes perciben a la música a través del oído, pero no todos la escuchan de la misma manera. La sonoridad musical, como vertiente de análisis, da la coordenada posicional de las prácticas urbanas, en el territorio y en el tiempo. Si la información que arroja, obedece a la manera en cómo se escucha la música y a las asociaciones a las que da pauta una vez escuchada, entonces es necesario definir cuáles son estas maneras de escuchar y cómo es que se crean dichas asociaciones.

El habitante de la ciudad está sujeto a una multiplicidad de sonidos. Definir la manera en que está escuchando la música implica pensar, además de los sonidos que lo rodean, en las actividades que realiza a la par. Ya que son estas actividades las que dan forma al vínculo directo con el territorio, la música y quienes los viven. Revueltas, Copland y Adorno, plantean maneras y oídos con los cuales se escucha la música.

Revueltas (), expone que existen tres tipos de oídos: el grosero, llamado de este modo porque no ha sido instruido y no conoce la música; el teorizante, visto como el que sí puede diferenciar a la música de los sonidos ordinarios; y el oído teórico, dicho de aquel que tiene la capacidad incluso de componer y organizar los sonidos. En esta clasificación, el oído grosero, planteado peyorativamente, no es capaz de escuchar la música.
Sin embargo, al analizar lo vivido por los escuchas puede afirmarse que este oído se hace presente, no sólo por la falta de instrucción, sino a consecuencia de una saturación sonora.

Copland (1994), por su parte, esboza maneras de escuchar la música. A diferencia de Revueltas, las define a partir de la existencia de la música, es decir, el escucha puede diferenciar la música respecto de otros sonidos. Para él, el oído grosero no existe. Su propuesta sostiene que la música puede ser apreciada a través de tres planos: el sensual, el expresivo y el puramente musical.

El plano sensual, visto como aquel "en el que oímos la música sin pensar en ella ni examinarla en modo alguno." (Copland, 1994: 27). Se escucha música mientras se camina, corre, limpia,... La ciudad escuchada a través de los sonidos que se generan en ella y que agradan al oído, modifican los ambientes y contextualizan la experiencia urbana del escucha: el trinar de las aves, las gotas de lluvia, las campanas de la iglesia, el danzón de los domingos en las plazas públicas.

El plano expresivo, lo refiere al significado que el escucha da a la música detrás de las notas, y se considera difícil de definir con palabras, sobre todo en el caso de la música docta, ya que puede expresar "en diversos momentos, serenidad o exuberancia, pesar o triunfo, furor o delicia." (Copland, 1994: 30). Escuchar La Marcha de Zacatecas (Genaro Codina, 1892), podrá estar expresando furor, triunfo y alegría para quienes no vivieron las épocas revolucionarias. Su expresión implica fiesta, alegría, es una invitación a los eventos cívicos impuestos en las escuelas de nivel básico. La expresión de la música acentúa la experiencia si se escucha en este plano. No sería lo mismo ver la película de El padrino (Coppola, 1972), sin la musicalidad de Nino Rota.

La emoción que desprende la música acentúa el discurso. Escuchar el Huelum del Instituto Polítécnico Nacional (IPN), o el Goya de la Universidad Nacional Autónoma de México (UNAM) (Porras universitarias), por ejemplo, pueden expresar furor y gloria si son enunciadas en una manifestación o en un partido de Águilas Blancas vs Pumas. Escucharlas en el Ángel de 
la Independencia en el 2014*, significó fraternidad y apoyo, insistiendo en que los estudiantes debían ser escuchados por todo el país, dado que los hechos ocurrieron en la avenida más vista de la Ciudad de México.

El plano puramente musical, según lo establece Copland (1994), no es un plano en el que cualquiera pueda posicionarse. Se tiene que tener, al menos, conocimiento de los principios básicos, ya que en este plano "...la música existe en cuanto a sus notas mismas y su manipulación” (Copland, 1994: 32). Su definición, de parte de Copland, es similar a la que hace Revueltas sobre el Oído Teorizante. En ambos se requiere de conocimiento previo, que le permita, al escucha, identificar, notas, timbres, ritmos...

Tanto Revueltas como Copland, tienen una idea de cómo la música es escuchada. Adorno (2009), por su parte, ve a la sociedad como una suma de oyentes, y a la música como un producto de consumo. $Y$ establece en cuatro su clasificación según el tipo de oyente: el cultural, el emocional, el resentido y el entretenido.

El oyente cultural sabe apreciar la música, dada su formación y capacidad de otorgarle un valor por su carácter musical. La ciudad escuchada, desde este oyente, refleja a un sector reducido de los habitantes de la ciudad, ya que el plano en que escucha es el puramente musical y da valor a la música en cuanto a su musicalidad, y no tanto a las relaciones que ésta crea con todos sus escuchas. A los siguientes tres tipos de oyentes se les mira otorgando un valor a las relaciones que crea la música con sus escuchas. El emocional, tiene una formación menos rígida que el anterior y valora la música en cuanto es motor de emociones, colocándolo en los planos placentero y expresivo. Es el oyente que posee mayor facilidad para relacionar sus emociones con las actividades que realiza y forja así vínculos afectivos.

El oyente resentido, al igual que el emocional, se guía por las emociones, en un sentido un tanto distinto, "aparentemente inconformista en su protesta contra el sistema musical..." (Adorno, 2009: 187). Aunque, Adorno hace referencia a la música docta, este oyente también se hace presente cuando se escucha música popular, generando con ello guetos. Así por su gusto por la música, la territorializa en cuanto genera relaciones con el lugar en el que fue escuchada.
El oyente entretenido, está utilizando la música como medio de confort y fuente de estímulos. La ciudad escuchada, desde estos cuatro oyentes, plantea a una ciudad figurada en los planos: placentero y expresivo, que se encuentran determinados a partir de las prácticas, intereses y emociones específicas del escucha.

La ciudad escuchada desde la música, en su mayoría, se da en los dos primeros planos que plantea Copland, el sensual y el expresivo. Si los habitantes de la ciudad están escuchando la música en estos dos planos y a veces hacen uso del oído grosero ¿Cuáles son las asociaciones a las que está dando pauta la música?

Un sonido escuchado, genera en el cuerpo, asociaciones que recaen en la experiencia del cuerpo en el mundo. Escuchar música contextualiza la escena e implica los diversos contextos, en que se vive: histórico, político o religioso. Los hechos se acompañan generalmente de sonidos, "Dado que el sonido procede siempre de una fuente, posee una dimensión espacial." (Fernández \& Martínez: 199). De modo que, al ser resultado de un hecho, es asociado de manera inmediata a cierta acción que se posiciona en el sitio donde se originó, proporcionando rumbo y distancia del lugar en el que fue generado, dando pauta, al escucha, de formar relaciones temporales y geográficas.

El eco de la sirena de una patrulla o una ambulancia, pueden ser asociados a un hecho específico. Una emergencia vial, por un lado, puede ser asociada a una peregrinación. Una vez enunciada el escucha, posiciona el sonido de manera inmediata en la avenida por la que está circulando y, a partir de ello, puede predecir la dirección que toma la patrulla, o si ésta se detiene; y establecer con claridad, según el caso, dónde están ocurriendo los hechos. Por otro lado, la música del carro de los helados, puede implicar contextos determinados. Por ejemplo, relacionarse con un día caluroso, una zona habitacional y muchos niños jugando. Asimismo, esta música puede incitar a la mente a pensar en una temporada del año en específico, la primavera o el verano, al inferir que son los climas calurosos lo que motivan a las personas a comprar helados.

En el caso de un lugar concurrido por muchos sonidos, cuando éstos están ausentes, es señal de que algo está pasando y repercute de forma inmediata en el escucha, dado que esta ausencia le agrega fuerza y dramatismo a

\footnotetext{
* Manifestaciones de estudiantes del IPN, en la Ciudad de México, en protesta al cambio del plan de estudios con apoyo de estudiantes de la UNAM.
} 
la escena vivida, denotando que está pasando algo distinto a lo que comúnmente sucede.

Las relaciones que se pueden generar, de cualquier hecho, casi siempre se vinculan a las actividades que se desarrollan a la par. Por lo que se considera que la música va de la mano con las prácticas que se realizan al momento de escucharla y, tendrán mayor fijación, según el plano en el que sea escuchada y si la vivencia fue o no significativa.

A continuación, se enlista una serie de actividades que se llevan a cabo mientras se encuentra presente la música. De igual manera, se vinculan los planos en los que pudo estar siendo escuchada.

Tabla 01. Los planos del escucha en cuatro puntos de la Cd. de México

\begin{tabular}{|c|c|c|c|c|}
\hline \multicolumn{4}{|c|}{ Actividade } & \multirow[b]{2}{*}{ Oyente } \\
\hline Lugar & $\begin{array}{c}\text { Música } \\
\text { escuch } \\
\text { ada }\end{array}$ & $\begin{array}{c}\text { s } \\
\text { acompaña } \\
\text { das por la } \\
\text { música }\end{array}$ & $\begin{array}{c}\text { Planos } \\
\text { del } \\
\text { escucha }\end{array}$ & \\
\hline $\begin{array}{l}\text { Calle } \\
\text { Mader } \\
\text { o, Col. } \\
\text { Centro } \\
\text { de Cd. } \\
\text { México }\end{array}$ & $\begin{array}{l}\text { Rock, } \\
\text { Gaitas, } \\
\text { Cumbia } \\
\text {, Salsa }\end{array}$ & $\begin{array}{l}\text { Caminar, } \\
\text { comprar, } \\
\text { vender, } \\
\text { comer, } \\
\text { beber, } \\
\text { bailar, } \\
\text { escuchar, } \\
\text { turistear, } \\
\text { platicar, } \\
\text { mirar, } \\
\text { mendigar, } \\
\text {... }\end{array}$ & $\begin{array}{l}\text { Placent } \\
\text { ero y } \\
\text { oído } \\
\text { grosero, } \\
\text { dada la } \\
\text { cantidad } \\
\text { de } \\
\text { música } \\
\text { present } \\
\text { e. }\end{array}$ & $\begin{array}{l}\text { Entreteni } \\
\text { do }\end{array}$ \\
\hline $\begin{array}{l}\text { Parque } \\
\text { México }\end{array}$ & $\begin{array}{l}\text { Rock, } \\
\text { Charles } \\
\text { tón }\end{array}$ & $\begin{array}{l}\text { Ejercitarse } \\
\text {, pasear } \\
\text { perros, } \\
\text { jugar, } \\
\text { caminar, } \\
\text { leer, } \\
\text { comer, } \\
\text { andar en } \\
\text { bicicleta, } \\
\text {... }\end{array}$ & $\begin{array}{l}\text { Placent } \\
\text { ero, } \\
\text { expresiv } \\
\text { o y oído } \\
\text { grosero. }\end{array}$ & $\begin{array}{l}\text { Entreteni } \\
\text { do }\end{array}$ \\
\hline $\begin{array}{l}\text { Zócalo } \\
\text { de la } \\
\text { Ciudad } \\
\text { de } \\
\text { México }\end{array}$ & $\begin{array}{l}\text { Salsa y } \\
\text { las } \\
\text { campan } \\
\text { as de la } \\
\text { catedral } \\
\text {. }\end{array}$ & $\begin{array}{l}\text { Bailar, } \\
\text { cantar, } \\
\text { escuchar, } \\
\text { vender, } \\
\text { comprar, } \\
\text { caminar, } \\
\text { fotografiar } \\
, \ldots\end{array}$ & $\begin{array}{l}\text { Placent } \\
\text { ero y } \\
\text { expresiv } \\
\text { o. }\end{array}$ & $\begin{array}{l}\text { Entreteni } \\
\text { do y } \\
\text { emocion } \\
\text { al }\end{array}$ \\
\hline
\end{tabular}

\begin{tabular}{|c|c|c|c|c|}
\hline $\begin{array}{l}\text { Garibal } \\
\text { di, Cd. } \\
\text { de } \\
\text { México }\end{array}$ & $\begin{array}{l}\text { Salsa, } \\
\text { Mariach } \\
\text { i, }\end{array}$ & $\begin{array}{l}\text { Bailar, } \\
\text { cantar, } \\
\text { escuchar, } \\
\text { vender, } \\
\text { comprar, } \\
\text { caminar, } \\
\text { fotografiar } \\
\text {, beber, } \\
\text { comer, ... }\end{array}$ & $\begin{array}{l}\text { Placent } \\
\text { ero y } \\
\text { expresiv } \\
\text { o. }\end{array}$ & $\begin{array}{l}\text { Entreteni } \\
\text { do, } \\
\text { resentid } \\
\text { o y } \\
\text { emocion } \\
\text { al. }\end{array}$ \\
\hline
\end{tabular}

La música puede ser fuente de información que contextualiza a los hechos en el tiempo y en el territorio, siempre y cuando, el escucha, pueda posicionarse dentro de cualquiera de los planos que sugiere Copland. Ante un oído grosero, la música no se registra en la memoria como parte de la experiencia, ni del territorio, pues le es ajena. La música se registra, como parte de la experiencia, cuando es escuchada en el plano sensual, en el expresivo o en el puramente musical. Ya que cuando el habitante escucha, se crean los vínculos con las prácticas urbanas y, por consiguiente, con el territorio. Aunque el valor otorgado dependerá de cómo se posicione la vivencia en el lugar, con respecto a las vivencias anteriores.

Un sonido asociado emocionalmente puede dar pauta a coordenadas, según los contextos y las experiencias de los escuchas. Si se plantea que el lugar, en el tiempo y en el territorio, está determinado por la experiencia urbana, el significado de dicha experiencia se convierte en ordenada del hecho, posicionando la experiencia en el territorio y en la memoria del escucha. Esta relación está dejando de lado a todo sonido escuchado no significativo. En este sentido, lo evocado por la música, además de posicionar lugares en el tiempo y en el territorio, también posiciona emociones vividas por el escucha.

Figura 01. Sistema de coordenadas de lo evocado por un sonido signado. 


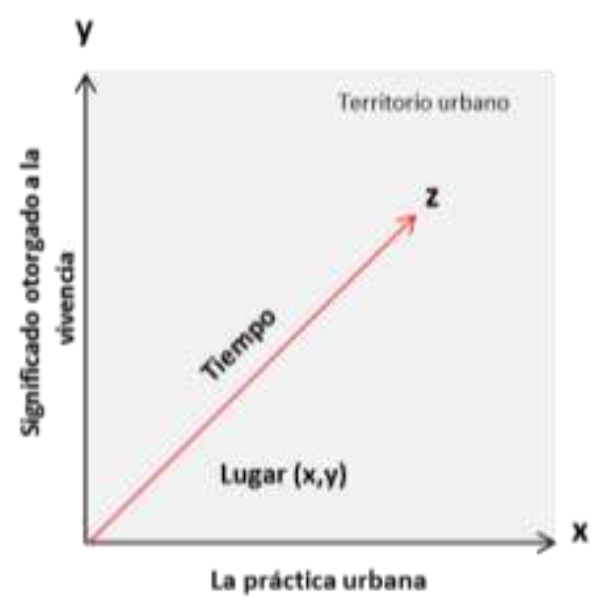

"Espacio y tiempo no son cosas que se perciben, sino modos de percibir, formas de dar un sentido a la sensación" (Durant, 1978: 310). El lugar y el tiempo, evocados por la música, figuran un territorio un tanto diferente, ya que se configura a partir de cómo es que los habitantes recuerdan las vivencias. El significado otorgado a las prácticas urbanas configura las vivencias y el lugar en el territorio. Su posición en el tiempo la coloca en la tercera dimensión; es decir, el lugar en un momento determinado de la vida del habitante. La coordenada posicional la dan las afecciones y la práctica urbana. Este cruce, entonces, es el que determina la posición en tiempo y lugar, y radica en la manera en la que se evoca determinada experiencia. En este caso, si la evocación es producto de un sonido, los cruces que se generan parten de las emociones que despiertan este hecho y de la manera en la que el escucha está escuchando la música.

El habitante de la ciudad, la mayor parte del tiempo, se encuentra escuchando en el plano sensual, dado que se encuentra inmerso en las actividades cotidianas. Sin embargo, cuando tiene la oportunidad, se puede posicionar en el plano expresivo, dotando de significado, tanto lo que escucha, como las experiencias vividas a la par de lo escuchado. La música, al ser un hecho universal, está presente en todas partes, y es escuchada mientras se deambula por la ciudad, privando al escucha de la oportunidad de elegir qué escuchar. Así el bagaje cultural se enriquece, ya que el escucha forja la experiencia urbana no únicamente con la música de preferencia, sino también, con la que se topa de manera cotidiana.

2.1 El género musical

Las asociaciones que se pueden generar con la música son muchas y pueden variar según el plano del escucha. Hablar, específicamente, de la sonoridad musical como elemento de análisis para entender a la ciudad, implica de manera directa al género. Dado que es, a través de éste, que se puede encontrar una relación con las zonas geográficas donde surge y/o es escuchada la música. Esta categoría de la música, además de clasificar rasgos musicales comunes, también aporta información de la cultura que la crea y escucha, es decir, información de los hechos en el tiempo.

Un género musical siempre está asociado a un estereotipo, que hace énfasis en las relaciones sociales y las características del lugar de origen. Por su ritmo, se coloca en una dimensión temporal que no siempre se relaciona con la fecha en la que se creó o con la época de apogeo; sino con la época en la que se escuchó dentro de los entornos sociales en que se posicionan las experiencias del escucha. "El arte de 'dar vuelta' a las frases tiene como equivalente un arte de dar vuelta a los recorridos" (De Certau, 2000: 112).

El género musical que da origen a la música popular, es el Jazz. Surge a finales del siglo XIX y principios del siglo XX. La comunidad afroamericana le da origen, en las orillas del Río Misisipi, en Norteamérica. Así como este género puede ser asociado a una época y lugar en específico, lo mismo puede hacerse con todos y cada uno de los géneros musicales.

En la siguiente tabla, se da referencia de 17 géneros musicales, el lugar y el tiempo en el que surgen, y de algunas asociaciones que los habitantes responden en un muestreo realizado sobre Av. Reforma, en la Ciudad de México.

Tabla 02. La música popular y su posición geográfica.

\begin{tabular}{c|c|c|c} 
Género & $\begin{array}{c}\text { Lugar de } \\
\text { origen }\end{array}$ & $\begin{array}{c}\text { Año en } \\
\text { que se } \\
\text { hace } \\
\text { popular }\end{array}$ & $\begin{array}{c}\text { Lugares } \\
\text { asociados } \\
\text { (Centros de } \\
\text { ciudad, } \\
\text { barrios } \\
\text { populares, } \\
\text { cabarets, } \\
\text { cantinas, } \\
\text { auditorios, } \\
\text { plazas } \\
\text { públicas) }\end{array}$ \\
\hline Bolero & Cuba & 1840 & $\begin{array}{c}\text { Transporte } \\
\text { público, } \\
\text { plazas } \\
\text { públicas }\end{array}$ \\
\hline Tango & $\begin{array}{c}\text { Río de la } \\
\text { plata y } \\
\text { Argentina }\end{array}$ & $1860-$ & $\begin{array}{c}\text { Buenos Aires } \\
\text { (Argentina) y } \\
\text { Montevideo } \\
\text { (Uruguay) }\end{array}$ \\
\hline
\end{tabular}




\begin{tabular}{|c|c|c|c|}
\hline Danzón & Cuba & 1879 & $\begin{array}{l}\text { Cuba y } \\
\text { México }\end{array}$ \\
\hline Jazz & $\begin{array}{l}\text { Estados } \\
\text { Unidos }\end{array}$ & 1900 & $\begin{array}{l}\text { Nueva } \\
\text { Orleans }\end{array}$ \\
\hline Mariachi & $\begin{array}{c}\text { Nayarit y } \\
\text { Guadalajara }\end{array}$ & 1900 & $\begin{array}{c}\text { Guadalajara, } \\
\text { El Tenampa, } \\
\text { Garibaldi }\end{array}$ \\
\hline Blues & $\begin{array}{c}\text { Memphis } \\
\text { (Tennessee) }\end{array}$ & 1912 & Misisipi \\
\hline Mambo & Cuba & 1930 & $\begin{array}{l}\text { Salones de } \\
\text { baile }\end{array}$ \\
\hline Rumba & Cuba & 1930 & $\begin{array}{c}\text { El cine } \\
\text { mexicano de } \\
1950\end{array}$ \\
\hline Cumbia & $\begin{array}{c}\text { Colombia y } \\
\text { Panamá }\end{array}$ & 1940 & $\begin{array}{c}\text { Barrios } \\
\text { populares, } \\
\text { salones de } \\
\text { baile. }\end{array}$ \\
\hline Rock & $\begin{array}{l}\text { Estados } \\
\text { Unidos e } \\
\text { Inglaterra }\end{array}$ & 1950 & $\begin{array}{l}\text { Centros de } \\
\text { ciudad, } \\
\text { Parques, } \\
\text { Plazas } \\
\text { públicas }\end{array}$ \\
\hline Chachachá & Cuba & 1953 & $\begin{array}{c}\text { El cine } \\
\text { mexicano de } \\
1950\end{array}$ \\
\hline Salsa & $\begin{array}{l}\text { Estados } \\
\text { Unidos }\end{array}$ & 1960 & Cuba \\
\hline Rap & $\begin{array}{l}\text { Sur del } \\
\text { Bronx y } \\
\text { Harlem } \\
\text { (Nueva } \\
\text { York) }\end{array}$ & 1960 & $\begin{array}{c}\text { Barrios } \\
\text { populares }\end{array}$ \\
\hline Reggae & Jamaica & 1960 & $\begin{array}{c}\text { Centros de } \\
\text { ciudad }\end{array}$ \\
\hline Нip Нор & $\begin{array}{l}\text { Sur del } \\
\text { Bronx y } \\
\text { Harlem } \\
\text { (Nueva } \\
\text { York) }\end{array}$ & 1970 & Nueva York \\
\hline Punk & $\begin{array}{c}\text { Gran } \\
\text { Bretaña }\end{array}$ & 1970 & $\begin{array}{l}\text { La glorieta de } \\
\text { Insurgentes }\end{array}$ \\
\hline Reggaetón & Panamá & 1970 & $\begin{array}{l}\text { Estados } \\
\text { Unidos y } \\
\text { España }\end{array}$ \\
\hline
\end{tabular}

En la actualidad, el posicionamiento geográfico de los géneros musicales, no sólo se logra ver en las ciudades de origen. Los desplazamientos inter e intra-urbanos, están generando combinaciones culturales, llevando con ello a la música hacia otros sitios, en otras ciudades del mundo. Esta diversidad cultural que se está gestando con la combinación sonora, provoca, además de nuevas maneras de hacer música, una integración y aceptación ciudadana a lo nuevo y/o diferente.

Lo que el lector recibe no sólo es el sentido de la obra sino también, por medio de éste, su referencia a la experiencia que éste trae al lenguaje y, en último término, el mundo y su temporalidad que despliega ante ella.

(Ricoeur, 2004: 150)

Cabe precisar que el género musical lo determina, además de sus ritmos, una cultura específica. Departir de éste implica a la geografía urbana, a sus escuchas, sus costumbres, la política, la economía, la migración... Saber su procedencia ayuda a entender, no sólo los contextos vividos que dieron pie a determinada obra musical, sino, las formas de hibridación cultural a las que está dando pauta, ya que su adopción implicó, incluso de un aprecio artístico, una valoración del hecho musical.

\section{El escuchario}

Escuchario es un término creado a partir de la relación de escuchar. Si el imaginario es producto de la acción de imaginar, la acción de escuchar, siguiendo la misma idea, da forma al escuchario. Mientras uno se funda en las imágenes, el otro es detonado a partir de un sonido. Si bien ambos son complementos, una imagen no necesariamente viene acompañada de un sonido, es así que se considera necesario establecer un nombre específico que refiera a la acción de escuchar.

La música despierta al escuchario, es contenedora de experiencias y significados, ya que permite edificar, desde la memoria, ambientes y prácticas especificas relacionadas a la música que lo evocó. Es aquí donde los ambientes y prácticas construidas son producto de las interpretaciones del escucha; figuraciones que se presentan de manera efímera y que traen consigo sentimientos y emociones, dado el momento en que se generaron. Si la práctica se hace en la ciudad, estas construcciones tenderán a aportar información de los lugares vividos.

La ciudad, desde el escuchario, plantea una realidad fragmentada que parte de los hechos signados, de una interpretación y de las asociaciones que el escucha genera en torno a un hecho musical. Si, como menciona Schütz "...el significado de una vivencia varía según el momento desde el cual el yo lo observa" (), es, entonces, que estas construcciones se modelan un tanto diferentes cada vez que se presentan. Así como el punto de vista se ve afectado por las experiencias y el 
tiempo, las configuraciones de la ciudad, realizadas a partir del escuchario, también. Sin embargo, las pérdidas se consideran mínimas, ya que la música puede despertar con su sonoridad, incluso, los sentimientos vividos.

Este trabajo plantea que el escuchario da referencia de la ciudad desde tres enfoques: a). Como construcción de lo percibido: el escuchario urbano revela los lugares y las prácticas urbanas acorde al significado otorgado. b). Como construcción de lo imaginado: da los estereotipos asociados al lugar, los habitantes y las prácticas urbanas. c). Como configuración de lo deseado: revela la poética figurada en las ensoñaciones del escucha.

A continuación, con información de los muestreos y entrevistas a profundidad, recabadas en la Zona Metropolitana de la Ciudad de México, para esta investigación, se plantean los tres enfoques que hablan de la ciudad desde el escuchario.

a). Construcción de lo percibido

La construcción que se genera con el escuchario revela lo percibido por el escucha y puede dar una coordenada signada a partir de un momento vivido. Además, da certidumbre al escucha en su andar, cuando se reconoce en los lugares de la ciudad a través de sus experiencias.

Una vez que el escucha posiciona las experiencias en el territorio y las puede relacionar con una canción, también las está posicionando en la música. En los muestreos, los habitantes hicieron referencia a canciones que les recordaban la pérdida de seres queridos; tardes bohemias en familia, en el estado de Oaxaca; un momento agradable con buena compañía; un concierto de Roger Waters, con sus hermanas en el Foro Sol; el patio de la abuela; un viernes saliendo de la escuela; un día entre semana, por la tarde, en compañía de buenos amigos; y los recorridos de una juventud bailadora en la Nueva Atzacoalcos. La música data experiencias y revive en el escucha emociones y experiencias pasadas, así como una idea del lugar vivido.

"El amante disfruta sufriendo, le gustan los ademanes y estilemas que el sufrir trae consigo, porque el amor es una estética y su forma más distintiva es la música." (Fernández Porta, 2010: 23)

El escuchario, además de dar la coordenada, también conduce al escucha a un sentimiento vivido. Adamari (una de las encuestadas), por ejemplo, se quedó callada mientras recordaba con nostalgia un momento doloroso de su vida, la canción Tengo que colgar (Banda MS, 2016), le recordaba un rompimiento amoroso. Así, como ella, a Mayra, la canción Bye Bye (Vilma Palma e Vampiros, 1992), le significa el fin de una relación y un viaje en microbús a la altura de Av. Miramontes, en la Cd. de México. La vida desde el escuchario se narra a través del lugar y de las emociones vividas, ya que revive la escena. El escuchario es la narración de un momento vivido y la emoción que se recrea dependerá del punto en que se esté mirando.

\section{b). Construcción de lo imaginado}

Esta construcción reflejan las idealizaciones que se forman a partir de una canción o género musical, con respecto a lugares o personas. Lo que da forma a los estereotipos, asociados a determinado género musical. Por ello se habla de las relaciones que crea el escucha, a partir de una idealización de la música, las prácticas y los lugares donde los sectores de la población la hacen suya. Se da muestra de ello con estigmatizaciones realizadas, no únicamente por quienes escuchan la música, sino por quienes se sienten diferentes al preferir escuchar otro género musical. Un ejemplo se puede ver en una nota que publica el periódico El Universal, titulado "Firman para echar salsa, baile y 'nacos' del INBA y... ¡lo logran!” (Cultura). Donde claramente se advierte una ideología segregacionista, establecida por quienes se sienten conocedores de las artes.

El punto de vista se crea en torno a una idea que se tiene de los hechos. La música es reconocida cuando es estereotipada. De modo que puede ser relacionada con un lugar o hecho específico. Permitiendo, con ello, al escucha, identificar características de los lugares, de las personas y de las prácticas.

En las muestras tomadas, cuando se planteó la relación que tiene el reggaetón con un lugar de la ciudad, hubo quien lo relacionó con "los lugares feos de la ciudad" (Mayra), mecionando entre estos a Tepito, la zona Centro de la Ciudad México y a las zonas marginadas.

Así como con los bares juveniles; las escuelas secundarias, ya que es ahí donde se concentra el sector joven de la población que lo escuchan; y con Iztapalapa, por ser "un lugar de jóvenes desorientados" (Pablo). Cabe mencionar que las relaciones y adjetivos que se crean parten del punto de vista de los escuchas, del entorno cultural y de la manera en la que han sido vividas las experiencias.

Los eventos sonideros, por ejemplo, recrean a una sociedad bailadora y fiestera, que al masificarse, recorren, en sus inicios, los patios de las casas en algunas zonas de la Ciudad de México (La Nueva 
Atzacoalcos, El peñón de los Baños, Tepito, Neza, Santa Úrsula Coapa). Patios que resultaron pequeños ante la presencia sonidera y el agrado de sus aficionados, dando pauta a una apropiación de espacios públicos como la plaza y la calle. Estos lugares se convirtieron en sede de los bailes masivos en la década de los 70's y 80's. El gusto por el baile, la fiesta y el flirteo movía a distintos sectores de la población que provenían, tanto del antes llamado Distrito Federal, como de los municipios aledaños del Estado de México, ya que se decía "el que no sabe bailar no liga, no convive" (Ramírez, 2010: 6).

Los días de aquellos grandes bailes callejeros, que iniciaban cada 14 de octubre antes de las 11 de la mañana y terminaban al día siguiente en el corazón del barrio, sobre el Eje 1 Norte, quedaron en el recuerdo (Suárez \& Laura, 2014: 40).

Anunciados a todas voces, los eventos sonideros congregaban a la gente en todos los lugares en los que se presentaban y, aunque su auge lo tuvieron en la época de los 70's y 80's, en la actualidad aún se pueden escuchar en el transporte público y en los paraderos de autobuses. La información que contienen estas grabaciones, hace alusión a las colonias donde se presentaron y a los apellidos de algunas familias a través de saludos. Por lo que no es nada raro que en las muestras recabadas, aun no siendo todas en la Ciudad de México, relacionan a la cumbia sonidera con los patios de la casa de la abuela, los bailes organizados en sus colonias y, ya de manera más común, en la actualidad, a los salones de fiesta que se convirtieron en opción, dados los problemas que se generaban al convertirse en eventos masivos.

Tabla 06. Muestras de relaciones que se crean en torno a cuatro géneros musicales (Rock, Cumbia, Trova y Reggaetón).

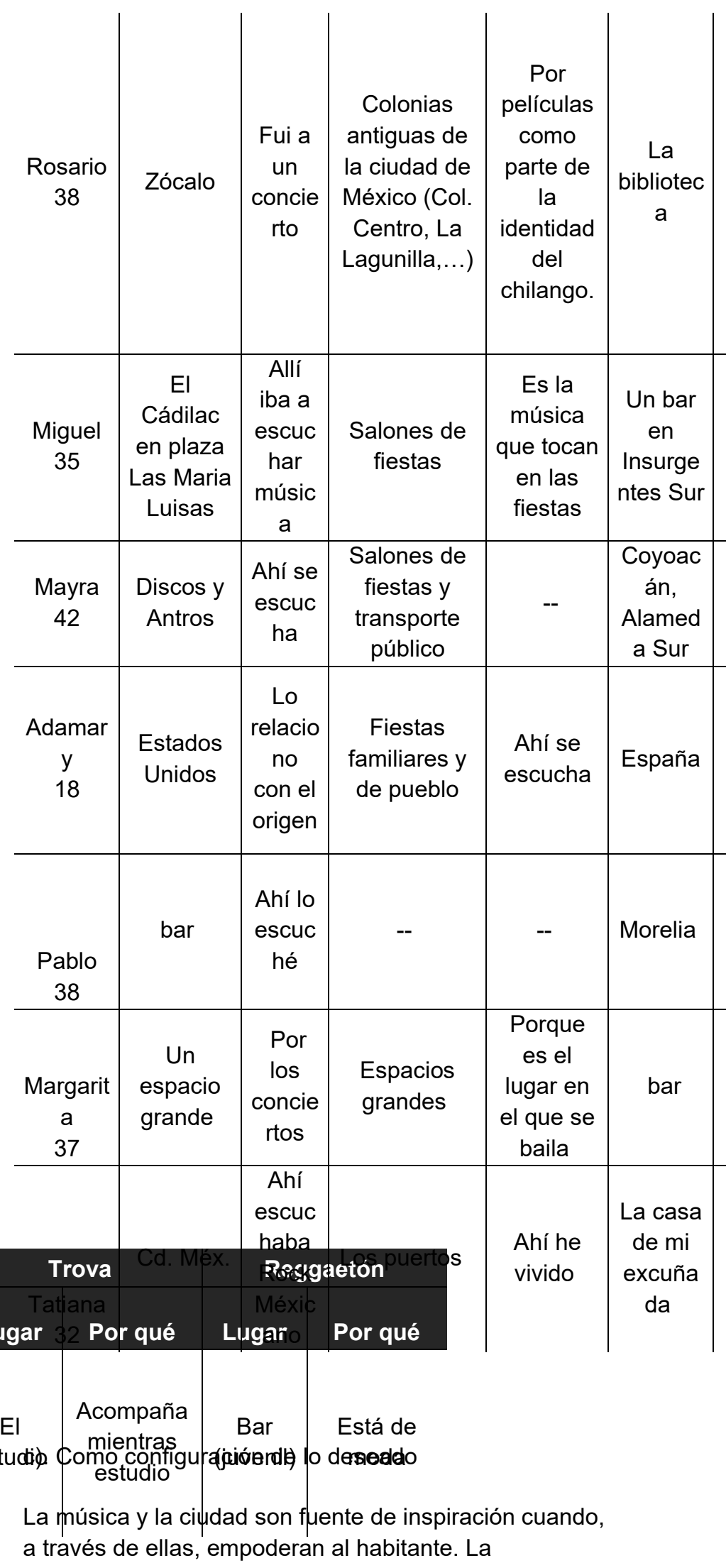


reciprocidad la crea el escucha, cuando de la una, surge la otra como obra de arte. La pauta se da en la calle, en los recorridos diarios de sus habitantes. El ritmo de la ciudad lo marca el habitar con cada paso que se da. Las posibilidades se vuelven infinitas, si se configuran en el deseo del escucha, acciones afectivas que emergen de las actividades cotidianas.

Cassirer, plantea que "En el acto mismo de la expresión lingüística, nuestras percepciones adquieren una nueva forma." (Cassirer, 1996: 58), por lo que las construcciones que se generen, en consecuencia a la música escuchada, no hacen referencia únicamente a los hechos percibidos a la par de ella o a las relaciones que se crean en cuanto ésta es escuchada, sino a una aspiración de ciudad que los escuchas construyen en el anhelo de encontrarla. Ya que lo que se configura, siempre podrá tener un matiz distinto al que fue, en un principio, concebido. Dado que las abstracciones hechas por el o los individuos que las percibieron, se revelan un tanto distintas a lo que actualmente es o fue. Destacan de los lugares, los elementos más representativos que les permiten a los habitantes figurar la escena de los hechos vividos.

La forma de apropiarse de la ciudad se modifica con el tiempo, y es en este transcurso que los matices tienden a variar, de modo que el foco de la lente con el que se observa siempre se encuentra ajustándose, definiendo a la ciudad en función de la experiencia vivida y de las relaciones que puede generar a partir de otras. El escuchario revela de la ciudad los andares de sus habitantes, su performance y su cultura.

Las canciones y los movimientos del cuerpo, en la ciudad, están construyendo en los escuchas un entramado musical, donde, a su vez, se está configurando la ciudad. La posición de las experiencias vividas, que se encuentran relacionadas con las canciones escuchadas, crean vínculos imaginarios emosignificativos. "El acto de caminar es al sistema urbano lo que la enunciación (el espeech act) es a la lengua o a las enunciaciones realizadas" (De Certau, 2000: 110).

Como construcción de lo imaginado, el escucha se apropia de la canción y la hace suya. Cuando el urbanita vive las canciones y puede asociarlas a lugares y personas determinadas, revive la experiencia como propia al asemejarlas con su vida real. En este caso, lo imaginado se recrea apartir de su enunciación narrativa: "Una ciudad no sólo es topografía, sino también utopía y ensoñación”. (Silva A. , 2006: 145). Las ciudades se tienen concebidas por algunas personas que vienen de provincia como "el lugar de las oportunidades". Y para otros que viven la ciudad a diario, en el tráfico y en el metro, se convierte en "la ciudad de las pesadillas". De ideas como estas es que se han configurado narrativas como: La estación del metro Balderas de Rockdrigo (1982), o En algún lugar de Duncan Dhu (1987).

Como configuración de lo deseado, los lugares asociados no responden precisamente a una experiencia vivida en el lugar, sino a una construcción, producto de los deseos. En una de las muestras que se tomó, la encuestada pudo relacionar a Cri Cri El grillo cantor (1963), con Chapultepec, y esto se debe a que las canciones de Gabilondo Soler, son asociadas a la infancia. Es así, que la memoria y la experiencia musical, se proyectan en la mente como situaciones vividas, y hacen presente al lugar cuando una canción lo evoca.

Asimismo, en una de las preguntas que se realizó en los muestreos tomados para este estudio ¿Qué ciudad te puedes imaginar si escuchas la canción de Amorcito corazón, cantada por Pedro Infante? Todos mencionaron a una ciudad de los años 40's- 50's en México, donde había más convivencia y respeto, donde su gente era pobre pero honrada, con ganas de trabajar; uno, incluso, mencionó que se imaginaba a una ciudad a blanco y negro. Lo que se pudo ver, con ello, fue a una ciudad figurada a partir de lo que el cine de los años 50 's mostró de la ciudad, y la idea de ciudad que los habitantes crearon con respecto a la época actual. Por lo que se dice que la ensoñación es la ilusión que crea el habitante en torno a lo real y a la fantasía. Aquí, el escuchario muestra el misticismo de la ciudad añorada $y$, en cierto modo, muestra una poética de la ciudad.

La sonoridad musical es símbolo de expresión y revela información de los deseos, las realidades y las necesidades. También, transforma los ámbitos sonoros, crea espacialidades que rompen con la trivialidad para algunas de las actividades urbanas, al generar, con ella, otras prácticas que no sólo recrean, sino unifican y posicionan a sus escuchas. Como transformadora de entornos, la música da al diseñador del territorio, pautas de articulación entre el lugar, la función y las prácticas urbanas.

\section{Conclusiones}

En la ciudad se encuentran inmersos mundos perceptivos e interpretativos que se figuran en cuanto sus habitantes definen a sus lugares. Pensarla desde los ambientes musicales ha permitido entenderla desde el compositor musical y el escucha. Desde ambos papeles, el habitante reinventa los contextos urbanos, influenciado por un carácter subjetivo, que le dota la 
vivencia. Mientras el compositor se regodea al crear, le da a los escucha distintas posibilidades de recrear, a partir de su influencia musical, mundos simbólicos. Los cuales a través de la música se han entendido desde tres vertientes.

La narrativa al ser una forma creativa en la que el autor de la obra muestra sus ideas, deja ver puntos de vista que se crearon, con los referentes vividos y ensoñaciones creativas, entonadas según el carácter que quieren transmitir los compositores. Su importancia radica en los hechos que destaca, y trasciende cuando da, a los escuchas, los elementos para crear, apartir de ella nuevos puntos de vista. Su trascendencia, en los estudios urbanos, la adquiere al ser referente de información posicional, de un punto de vista y hechos signados en cuanto es apropiada.

La fenomenología del sonido, ha dejado ver los lugares signados apropiadamente según la manera en la que el habitante escucha la música, el estado de ánimo en el que se encuentra y las prácticas urbanas que realiza a la par. El apego que las sonoridades crean con los escuchas ha mostrado las prácticas de los habitantes, las coordenadas signadas y con ello lugares y trayectos. Exponiendo, así, un territorio estereotipado por sus habitantes, desplazamientos, identidades, culturas y maneras de hacer ciudad y ciudadanos. Es así que tanto la narrativa, como la sonoridad hacen historia y describen hechos en el mundo, posicionándose, en algunos casos, como patrimonio cultural en la historia de las ciudades.

Del mismo modo, a través del escuchario se encontró a la ciudad como producto de una construcción simbólica que se desarrolla a partir de percepciones e interpretaciones a las que da pauta la vivencia. Dando cuenta de puntos de encuentro, significados y referentes que les permiten al escucha configurar a su ciudad a partir de una nota musical, una canción o un género en específico y que obedecen principalmente a los referentes teóricos o prácticos en los que se dan los contextos vividos.

\section{Referencias}

Adorno, T. W. (2009): Disonancias / Introducción a la sociología de la música. Madrid, España: Akal.

Cassirer, Ernst. El mito del Estado. México: Fondo de Cultura Económica, 1996.

Copland, Aaron. Como escuchar la música. México: Fondo de cultura económica, 1994.
Cultura, Periodistas. «Firman para echar salsa, baile y "nacos" del INBA y... ¡lo logran!» El Universal 26 de 05 de 2017.

Adorno, Th. W. Disonancias / Introducción a la sociología de la música. MAdrida, España: Akal, 2009.

De Certau, Michel. La invención de lo cotidiano. México D.F.: Universidad Iberoamericana, 2000.

Durant, Will. Historia de la Filosofía. La vida y el pensamiento de las más grandes filosófos del mundo. Diana, 1978.

Fernández Porta, Eloy. EROS La superposición de los afectos. México: Anagrama, 2010.

Fernández, Federico y Martínez. Manual Básico de lenguaje y narrativa audiovisual. Barcelona: Paidós, s.f.

Hegel, La dialéctica del Amo y el Esclavo en. Alexander Kojeve. Buenos Aires: La Pleyade, 1987.

Ramírez, Marco. Entre luces, cables y bocinas: el moviemiento sonidero. México: CENART, 2010.

Revueltas, José. La dialéctica de la conciencia. México: Era, 1986.

Ricoeur, Paul. Tiempo y narración. Cd. de México: Siglo XXI, 2004.

Schütz, Alfred. La construcción significativa del mundo social. Barcelona: Paidos, 1993.

Silva, Amando. Imaginarios urbanos. Bogotá: Arango Editores, 2006.

Silva, Armando. Imaginarios urbanos. Bogotá: Arango Editores, 2006.

Sontang, Susan. Contra la interpretación. Barcelona: Edición Against interpretation and other essays, 1984.

Suárez, Mariana y Gómez Laura. «Los sonideros callaron: festeja Tepito aniversario sin tumultuosos bailes.» La jornada 15 de octubre de 2014: 40

Tamburrini, Roberto. La ciudad y la música Alma Delia Juárez Sedano. 2015.

Viñuela, Eduardo. «El espacio urbano en la música popular: de la apropiación discursiva a la mercantilización.» Trípodos (2010): 15-28. 